\title{
Stearic acid, an Essential Growth Factor for Trypanosoma cruzi
}

\author{
By G. J. BONÉ AND G. PARENT \\ Laboratoire de Parasitologie Expérimentale, Institut pour la Recherche Scientifique et \\ Appliquée au Katanga (IRSAK), Elisabethville, Katanga
}

(Received 14 September 1962)

\section{SUMMARY}

The function of serum in the composition of culture media for trypanosomes was investigated with Trypanosoma cruzi. Serum supplies stearic acid, essential for the growth of this trypanosome. A liquid heat-sterilizable medium, composed of peptone and known chemicals is described. The growth of T. cruzi in this medium reached $70 \times 10^{6}$ trypanosomes $/ \mathrm{ml}$.

\section{INTRODUCTION}

Many aspects of the problem of the cultivation of trypanosomes remain unsolved. The trypanosomal stage, present in the blood, cannot be grown in vitro; the forms which multiply in culture are always these which develop in the invertebrate vectors. Each species has its own growth requirements and a successful defined medium has not yet been described; the presence of serum or whole blood is usually essential. The less exacting trypanosomes are parasites of cold-blooded vertebrates. Boné \& Steinert (1956) described a heat-sterilizable medium in which Trypanosoma mega, parasite of Bufo regularis, multiplied freely. This medium, whose main constituents are a peptone and a liver extract, is limpid and stable and has been used in further investigations. This tryptose liver medium does not support the growth of trypanosome parasites of mammals, even of those which are the easiest to grow in vitro, namely the trypanosomes of the group lewisi and cruzi. In the present work, we have tried to improve the culture methods for Trypanosoma cruzi in order to obtain a limpid and stable medium and to identify some of the growth factors required. The media generally used for the cultivation of $T$. cruzi are biphasic: a liquid phase overlays a solid base; they all contain whole blood or egg (Novy \& McNeal, 1904; Senekjie, 1943; Chang, 1947). Though excellent for stock cultures, these media are not convenient for experimentation because of their complexity and their heterogeneity due to protein precipitates and agar aggregates. By using a cellophan bag technique, Tobie \& Rees (1948) showed that $T$. cruzi could grow in the liquid phase of a diphasic medium. A liquid medium was described by Warren (1960), but its complex composition (brain heart infusion and filtrate of coagulated whole blood) makes identification of the essential factors difficult. Partially defined media were used by Sampath \& Little (1949) and Little \& Oleson (1951), but agar and erythrocytes were still added. Citri \& Grossowicz (1955) reported their results with a partially defined medium in which the only complex component was a casein hydrolysate. We tested this medium, but did not obtain 
satisfactory growth. In the present work, starting from the medium described by Boné \& Steinert (1956) for T. mega, we have found that the addition of calf serum or egg yolk is necessary for the growth of $\boldsymbol{T}$. cruzi; the active principle has been identified as stearic acid.

\section{METHODS}

Organisms. Our strain of Trypanosoma cruzi was obtained 5 years ago from the Institut de Médecine Tropicale, Antwerp, Belgium. It was maintained simultaneously in our tryptose liver serum medium with weekly subculture, and in the medium described by Chang (1947) with fortnightly subculture.

Culture media. Several media were used in this work. The tryptose liver medium of Boné \& Steinert (1956) was used as the basal medium to be supplemented by various nutrients. Its composition was (g./l.): Bacto-Tryptose (Difco), 15; dehydrated liver infusion (Oxoid), 1 ; glucose, 2; haemin, $0.02 ; \mathrm{NaCl}, 4 ; \mathrm{Na}_{3} \mathrm{PO}_{4}$. $12 \mathrm{H}_{2} \mathrm{O}, 5 ; \mathrm{KCl}, \mathbf{0} \cdot 4$; dissolved in twice-distilled water. Tryptose liver serum medium was obtained by adding 1 vol. of partially deproteinized calf serum (prepared as described below) to 2 vol. of double-strength tryptose liver medium +1 vol. twicedistilled water. The deproteinized calf serum was prepared by diluting calf serum with an equal volume of $0.1 \mathrm{M}-\mathrm{NaH}_{2} \mathrm{PO}_{4}$ adjusting to $\mathrm{pH} \mathrm{5.6}$ and autoclaving for $30 \mathrm{~min}$. at $115^{\circ}$. The protein precipitate was removed by centrifugation and the solution adjusted to $\mathrm{pH} 7 \cdot 6$. When stored in the frozen state, this solution keeps its activity.

Medium $\mathbf{T} 1$ was the same as the tryptose liver medium with the exception that the liver infusion was replaced by: thiamine $1 \mathrm{mg}$./l. and folic acid $3 \mathrm{mg}$./l.

Medium $\mathbf{T} \mathbf{2}$ was like medium $\mathrm{T} \mathbf{1}$ but with addition of stearic acid. It therefore contained: Bacto-Tryptose, 15 g.; glucose, $2 \mathrm{~g}$; ; thiamine, $1 \mathrm{mg}$.; folic acid, $3 \mathrm{mg}$.; haemin, $20 \mathrm{mg}$.; sodium stearate, $25 \mathrm{mg}$.; NaCl, 4 g.; $\mathrm{Na}_{3} \mathrm{PO}_{4} \cdot 12 \mathrm{H}_{2} \mathrm{O}, 5 \mathrm{~g}$.; KCl, $0 \cdot 4 \mathrm{~g}$.; twice-distilled water, $1.000 \mathrm{ml}$. Sodium stearate was added as a colloidal solution prepared for each batch of medium: $20 \mathrm{mg}$. stearic acid $+98.3 \mathrm{ml}$. distilled water $+1 \cdot 7 \mathrm{ml} .0 \cdot 1 \mathrm{~N}-\mathrm{NaOH}$ were heated at $70^{\circ}$ and stirred during $30 \mathrm{~min}$.

The tryptose liver medium or $\mathbf{T} 1$ medium were used in experiments for growth factor identification. They were supplemented with solutions of selected fatty acids dissolved in ethanol, $0.05 \mathrm{ml}$. volumes being added to each tube.

All the media were adjusted to $\mathrm{pH} 7 \cdot 6$, dispensed in cotton-wool-plugged vessels and sterilized by autoclaving at $115^{\circ}$ for $10 \mathrm{~min}$.

Chemicals. With the exception of arachidic and behenic acids which came from Fluka A.G., Buchs, Switzerland, all the fatty acids came from the Mann Research Laboratories, New York. The Tween 60 was supplied by the Atlas Powder Co, Wilmington, Delaware, U.S.A. and the butyl stearate by Schuchardt, Munich; the latter product was twice distilled under reduced pressure before use. Egg yolk, thiamine and folic acid were obtained from the General Biochemicals, Chagrin Falls, Ohio, U.S.A. Purified phospholipids were kindly given by Miss Faure, Institut Pasteur, Paris. All other reagents were of A.R. grade.

Growth experiments. Stock cultures were maintained in $200 \mathrm{ml}$. Erlenmeyer flasks containing $25 \mathrm{ml}$. medium. The experimental cultures were made in $15 \times$ $125 \mathrm{~mm}$. test tubes containing $4 \mathrm{ml}$. medium. Each tube was inoculated with $0.2 \mathrm{ml}$. of a 5 to 8 day culture containing $50-70 \times 10^{6}$ flagellates $/ \mathrm{ml}$. When testing 
the activity of sodium stearate, its concentration in the inoculum was decreased to a minimum by one transfer into a medium containing only $5 \mu \mathrm{g}$. sodium stearate/ ml. After 5-8 days of incubation the trypanosomes were centrifuged down and resuspended in the required volume of $\mathbf{T} 1$ medium. Cultures were maintained at $27^{\circ}$ on a roller tube apparatus. When the medium was clear, the growth could be measured by optical density readings at $680 \mathrm{~m} \mu$ with a Hilger Biochem spectrophotometer. Counts in a haemocytometer were made in the case of cloudy media and for the determination of growth curves on which each point recorded represented the mean value obtained by counting four cultures.

\section{RESULTS}

The tryptose liver medium described by Boné \& Steinert (1956) for Trypanosoma mega did not support the growth of $T$. cruzi, but it was used as a convenient basal medium for further experiments. With the addition to this medium of $2 \%(\mathrm{v} / \mathrm{v})$ fresh calf serum, a rich growth was obtained. The active factor in the serum was heat stable: when the serum, diluted with an equal volume of buffer to $\mathrm{pH} \mathbf{5 \cdot 6}$, was heated for $30 \mathrm{~min}$. at $115^{\circ}$, most of the protein precipitated and the activity remained in the slightly opalescent supernatant fluid. This deproteinized fraction of serum was used to supplement the tryptose liver medium.

The new medium, called tryptose liver serum, presented obvious advantages: it was clear, stable and heat sterilizable. It has been used for stock and experimental cultures. Our strain of Trypanosoma cruzi has been maintained in it during $\mathbf{1 5 0}$ transfers over a period of 3 years. The flagellates were subcultured every 8 days, at the end of exponential growth; they were still motile in 6-week-old cultures. The growth curve obtained with this medium is shown in Fig. 1: the maximum yield, reached after 11 days' incubation, varied from 35 and $45 \times 10^{6}$ organisms $/ \mathrm{ml}$. The tryptose liver serum medium contained three complex components namely, from muscle, liver and serum. We next tried to separate and identify the essential factors in each extract and to replace them by defined chemicals.

Replacement of serum. The isolation of the active principle present in serum was difficult because of its low concentration. We looked for a richer source of this factor and found it in egg yolk. By extracting lyophilized egg yolk with cold solvents, it was found that the active principle was very slightly soluble in water, soluble in methanol and insoluble in acetone. These solubility characteristics are those of lecithin, a component of egg yolk. Egg-yolk lecithin was tested and supported the growth of Trypanosoma cruzi when added to the tryptose liver medium at $500 \mu \mathrm{g} . / \mathrm{ml}$. Twenty-seven subcultures were made in this medium without any change in the growth rate of the flagellates. Other phospholipids were tested; a cardiolipid and phosphatidic acid were without action, while phosphatidyl inositol in the same concentration range showed the same activity as the egg-yolk lecithin.

As rather large amounts of lecithin or phosphatidyl inositol were required, we supposed that the activity was not due to the phospholipids as such, but to a common constituent of their molecules. Glycerol, choline and inositol had no action, but the fatty acids isolated by hydrolysing lecithin by the method of Hanahan, Turner \& Jayko (1951) replaced the lecithin completely. From the composition of egg-yolk lecithin, we thought that stearic acid might be responsible 
for the observed activity. We tested a series of saturated and unsaturated fatty acids (from $\mathrm{C}_{12}$ to $\mathrm{C}_{22}$ ): linoleic and arachidic acid were without action; lauric, myristic, palmitic, palmitoleic, linolenic, oleic and arachidonic acid had an adverse effect. Two acids only, stearic $\left(\mathrm{C}_{18}\right)$ and to a lesser extent behenic acid $\left(\mathrm{C}_{22}\right)$ promoted growth. When the tryptose liver medium was supplemented with $25 \mu \mathrm{g}$. stearic $\mathrm{acid} / \mathrm{ml}$, $70 \times 10^{6} \mathrm{organisms} / \mathrm{ml}$. were counted, while only $40 \times 10^{6}$ organisms $/ \mathrm{ml}$. were obtained with $100 \mu \mathrm{g}$. behenic acid $/ \mathrm{ml}$.

The poor solubility of stearic acid made the preparation of media rather difficult; we looked thus for water soluble derivatives. The butyl ester was toxic but the results obtained with the sodium salt and with Tween 60 were very satisfactory (Fig. 1). The richest growth being obtained with sodium stearate, all further experiments were made with this salt.

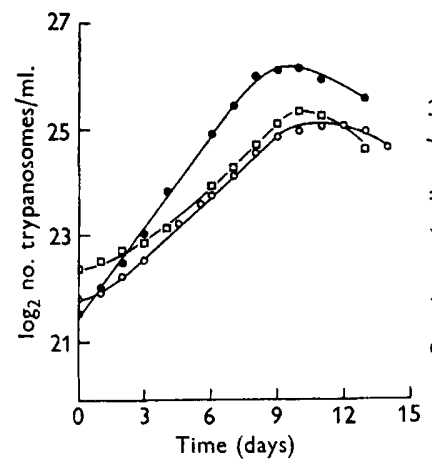

Fig. 1

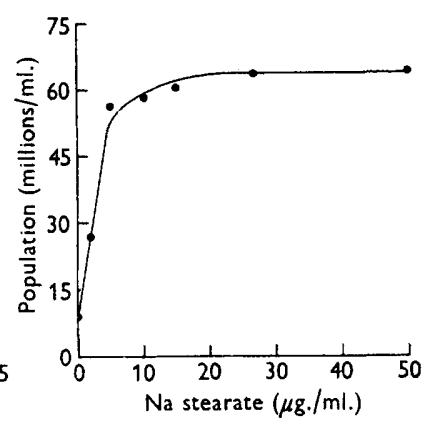

Fig. 2

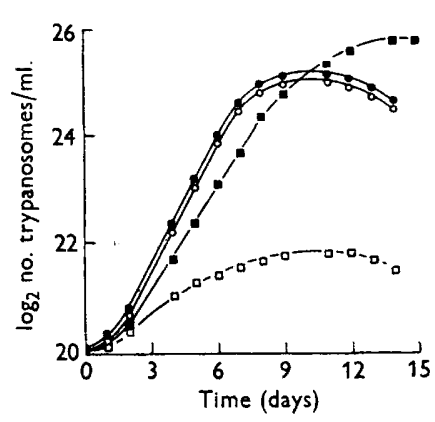

Fig. 3

Fig. 1. Growth of Trypanosoma cruzi in tryptose liver medium differently supplemented: $O$, With serum; $\square$, with $60 \mu \mathrm{g}$. Tween $60 / \mathrm{ml}$; 0 , with $25 \mu \mathrm{g}$. sodium stearate $/ \mathrm{ml}$.

Fig. 2. Dose response of Trypanosoma cruzi to sodium stearate. Cultures were incubated until a stable population was reached.

Fig. 3. Influence of carbon dioxide on the growth of Trypanosoma cruzi without stearate ( $\mathrm{T} 1$ medium): in air, $\square$; in $\operatorname{air}+\mathrm{CO}_{2} 5 \%(\mathrm{v} / \mathrm{v}), 0$. With stearate ( $\mathrm{T} 2$ medium): in air, a in air $+\mathrm{CO}_{2} 5 \%(\mathrm{v} / \mathrm{v})$, 0 .

To determine the relation between stearate concentration and growth, sodium stearate in aqueous solution was added to the $\mathrm{T} \mathbf{1}$ medium (see below). In this medium, the liver extract, likely to contain fatty acids, had been replaced by thiamine + folic acid. Tryptose, a tryptic digest of muscle, was the only complex component still present. A maximum growth was obtained around $20 \mu \mathrm{g}$. stearate/ $\mathrm{ml}$. (Fig. 2) and a concentration of $25 \mu \mathrm{g}$. stearate/ml. was adopted in media for stock cultures.

Replacement of liver extract. Having found that serum could be replaced by sodium stearate, we examined the active factors present in the liver extract. We tested the activity of many substances, including those already identified as nutrients or growth factors for Trypanosoma cruzi (Senekjie, 1943; Sampath \& Little, 1949; Little \& Oleson, 1951; Citri \& Grossowicz, 1955). When tryptose was the only undefined constituent of the medium, it appeared that two factors only needed to be supplied by the liver extract, namely, thiamine and folic acid. The optimum 
concentration for thiamine was $1 \mu \mathrm{g} . / \mathrm{ml}$. and for folic acid $3 \mu \mathrm{g} . / \mathrm{ml}$. This new medium (T 2 medium) has supported the growth of Trypanosoma cruzi through 75 subcultures over a period of 18 months. An average population of 50-70 $\times 10^{6}$ trypanosomes $/ \mathrm{ml}$. was reached at the end of the growth phase.

Influence of carbon dioxide. Carbon dioxide accelerated only slightly the growth of Trypanosoma cruzi in the $\mathbf{T} \mathbf{2}$ medium, but it had a significant growth-promoting activity in media deprived of stearate. When the culture vessels were plugged with cottonwool with access to air, $T$. cruzi grew only poorly in the absence of stearate. When the cotton-wool-plugged tubes were kept in a rotating jar filled with air + $5 \%(\mathrm{v} / \mathrm{v}) \mathrm{CO}_{2}$ the growth became very abundant, comparable to the multiplication of $T$. cruzi in an optimum medium containing stearate (Fig. 3).

\section{DISCUSSION}

Serum is a common constituent in culture media for trypanosomes. Its function has been ascribed either to some chelating or detoxifying effect or to the supply of essential nutritional factors. Our experiments with Trypanosoma cruzi support this last hypothesis: the serum supplies this trypanosome with an essential nutrient, stearic acid. A requirement for long-chain saturated fatty acids is unusual. It has, however, been already described for Paramecium, requiring stearic acid (Miller \& Johnson, 1960) and for Trichomonas, which needs oleic + stearic acids (Shorb \& Lund, 1959). The requirement for stearic acid, observed with $T$. cruzi, may prove to be common to many trypanosome parasites of mammals but conclusive evidence will be difficult to obtain since most species need additional growth factors present in erythrocytes. Some trypanosomes, however, are probably able to synthesize stearic acid: T. mega, parasite of an amphibian, does not need stearic acid as a nutrient (Boné \& Steinert, 1956). Of the fatty acids tested, whether saturated or unsaturated from $\mathrm{C}_{12}$ to $\mathrm{C}_{22}$, only stearic acid and to a lesser extent behenic acid induced the growth of $T$. cruzi. The observed activity of the $\mathrm{C}_{18}$ and $\mathrm{C}_{22}$ saturated acids as compared with the absence of growth-promoting action by arachidic acid $\left(\mathrm{C}_{20}\right)$, seems hard to explain. We suspected an impure sample of behenic acid containing some stearic acid, but a paper chromatograph of our sample of behenic acid did not show stearic acid; amounts of stearic acid sufficient to give the amount of growth observed would have been detected. The lower final yield obtained with Tween 60 can be explained by the fact that it contains, in addition to stearic acid, appreciable amounts of palmitic, oleic and myristic acid (Shorb \& Lund, 1959); these last three fatty acids, separately, are toxic for $T$. cruzi.

The role of stearic acid in the growth of Trypanosoma cruzi is unknown. The growth stimulating action of carbon dioxide has probably a bearing on this problem. With the two species of trypanosomes examined, this action seems to be linked to a requirement for stearic acid. Carbon dioxide was only stimulatory for $T$. cruzi in a medium lacking stearic acid but had no influence when this was supplied. With T. mega, which does not require stearic acid as a nutrient, carbon dioxide was also without effect. These observations accord with the present knowledge of the biosynthesis of fatty acids: the first step being the carboxylation of acetyl-CoA with carbon dioxide to give malonyl-CoA (Wakil, 1962).

Our T 2 medium is an improvement on the usual culture media for Trypanosoma 
cruzi. All its constituents are commercial products and the tryptose is the only one of unknown composition. The medium can be autoclaved, it is limpid and allows growth determination by turbidimetry. The yield, $70 \times 10^{6}$ trypanosomes $/ \mathrm{ml}$., compares favourably with that obtained with the more complex culture media commonly used.

The initial stages of this work were undertaken in the Microbiology Unit, Department of Biochemistry, Oxford University. One of us (G.B.) is indebted to Professor D. D. Woods, F.R.S., for his hospitality, encouragement and helpful advice. The authors express their gratitude to the Institut belge pour l'encouragement de la Recherche Scientifique Outre-Mer (IBERSOM) for the substantial grant they both received.

\section{REFERENCES}

Boné, G. J. \& Steinert, M. (1956). Isotopes incorporated in the nucleic acids of Trypanosoma mega. Nature, Lond. 178, 308.

Chang, S. L. (1947). Studies on haemoflagellates. I. A semi-solid medium and a fluid medium with a solid base for growing various species of Leishmania and Trypanosoma cruzi. J. infect. Dis. 80, 164.

Citri, N. \& Grossowicz, N. (1955). A partially defined culture medium for Trypanosoma cruzi and some other Haemoflagellates. J. gen. Microbiol. 13, 273.

Hanahan, D. J., Turner, M. B. \& JaYko, M. E. (1951). The isolation of egg phosphatidyl choline by an adsorption column technique. J. biol. Chem. 192, 623.

Little, P. A. \& Oleson, J. J. (1951). The cultivation of Trypanosoma cruzi. J. Bact. 61, 709.

Miller, C. A. \& Johnson, W. H. (1960). Nutrition of Paramecium. A fatty acid requirement. J. Protozool. 7, 297.

Novy, F. G. \& MCNeal, W. J. (1904). On the cultivation of Trypanosoma brucei. J. infect. Dis. $1,1$.

Sampath, A. \& Little, P. A. (1949). Cultivation of Trypanosoma cruzi in liquid media. J. Bact. 57, 265.

SenekJie, H. A. (1943). Biochemical reactions, cultural characteristics, and growth requirements of Trypanosoma cruzi. Amer. J. Trop. Med. 23, 523.

Shorb, M. S. \& Lund, P. G. (1959). Requirement of trichomonads for unidentified growth factors, saturated and unsaturated fatty acids. J. Protozool. 6, 122.

Tobie, E. J. \& ReEs, C. W. (1948). The cultivation of Trypanosoma cruzi in dialysate medium. J. Parasit. 34, 162.

WAKIL, S. J. (1962). Lipid metabolism. Annu. Rev. biochem. 31, 369.

Warren, L. G. (1960). Metabolism of Schizotrypanum cruzi. J. Parasit. 46, 529. 